\title{
Seismic Safety Assessment of Buildings with Fly-Ash Concrete
}

Kirtikanta Sahoo ${ }^{1}$; Prateek Kumar Dhir ${ }^{2}$; Peri Raghav Ravi Teja ${ }^{3}$; Pradip Sarkar $^{4}$; and Robin Davis ${ }^{5}$

${ }^{1}$ Assistant Professor, Department of Civil Engineering, KIIT University, Bhubaneswar 751024, India.

Email: $\underline{\text { sahoo.kirti@gmail.com. }}$

${ }^{2} \mathrm{Ph}$. D. Scholar at Department of Civil and Environmental Engineering, University of Strathclyde,

Glasgow G1 1XJ, United Kingdom. Email: prateek.dhir@strath.ac.uk (corresponding author)

${ }^{3}$ M. Tech. Scholar at Department of Civil Engineering, National Institute of Technology, Rourkela

769008, India. Email: prraviteja04@gmail.com.

${ }^{4}$ Professor, National Institute of Technology, Rourkela 769008, India. Email: sarkar.pradip@gmail.com.

${ }^{5}$ Assistant Professor, National Institute of Technology, Calicut 673601, India. Email:

robin.davisp@gmail.com.

\begin{abstract}
Sustainable concrete construction has encouraged the utilization of industrial wastes (fly ash, silica fume, ground granulated blast furnace slag, metakaolin, etc.) as a composite cementitious material due to its high pozzolanic activity. Among them, fly ash (FA) concrete is gaining high popularity in the construction industry due to its several benefits to the concrete structures with increased structural performance. In order to estimate the seismic performance of FA concrete buildings, a probabilistic study needs to be performed for its mechanical parameters at various performance limit states. Weibull, normal, log-normal and gamma distribution probability distribution models are considered for three goodness-of-fit tests such as the Kolmogorov-Smirnov (KS), Chi-square (CS) and log-likelihood (LK) tests. Among them, the lognormal distribution is found to be the closest distribution in describing the variations in the mechanical properties of FA concrete as compared to other distributions. It was observed that $20 \%$ to $40 \%$ partial replacement of FA with cement gives an improved performance to the structures with enhanced structural safety at economical cost.
\end{abstract}


Keywords: Variability, fly ash concrete, seismic hazard curve, fragility curve, reliability curve INTRODUCTION

Increasing growth of industries has increased the production of industrial waste which is greatly responsible for the present environmental damage and there is an urgent need for their effective utilization. Among the various types of supplementary materials, fly ash (FA) was introduced in the construction industry due to their pozzolanic activity which subsequently leads to a reduction of global $\mathrm{CO}_{2}$ footprint significantly. So, the minimal use of Portland cement can significantly reduce the impact of the concrete industry on the environment. The increased popularity of FA concrete in recent years is due to the benefits like reduced water demand, improved workability, minimized crack formation by drying and thermal shrinkage, robustness against rebar corrosion, alkali-silica expansion, and sulfate attack (Saha et al. 2018, 2019; Saha 2019; Saha and Sarker 2020).

The accurate evaluation of structural safety is based on the accurate prediction of the uncertainty associated with its mechanical properties. But, in conventional structural design, this aspect is always ignored. The deterministic assumption of the is not a realistic approach while considering the material parameters and due to this, probabilistic structural analysis is gaining popularity nowadays as it considers the uncertainty in material properties against natural loads such as earthquakes, wind, etc.

Campbell and Tobin (1967), Soroka (1968), Chmielewski and Konapka (1999), Graybeal and Davis (2008) studied on the variability of compressive strength of concrete and reported that the coefficient of variation in a normal distribution of a considered parameter doesn't exceed 15-20\% with a minimal skewness. Campbell and Tobin (1967) and Soroka (1968) found that at a high coefficient of variation, the skewness is significant and the lognormal distribution is found to be more rational to signify the tail areas of distribution as compared to normal distribution. Recently, concrete compressive strength variability was characterized by Chen et al. 2013 using several statistical standards. The available literature on the regular cement concrete may not be suitable to characterize the variability of FA concrete accurately, which raises a need for the design and safety assessment of the FA concrete buildings in the future. 
In this study, the mechanical properties of the FA concrete were experimentally tested and for the variability study, the normal and log-normal distributions are considered for its variability study. A best-fitted probability distribution function for concrete with altered amounts of FA is generated by adopting different statistical tests. Along with that, the relative dynamic performance of buildings built with a varying replacement of FA is compared with the regular reinforced concrete (RC) buildings for a selected site hazard condition.

\section{RESEARCH SIGNIFICANCE}

Literature on the probability distribution of mechanical properties of structure with normal concrete is available. However, the study of variability of concrete, prepared by the partial replacement of FA is quite rare. Mechanical properties of FA concrete are analytically described using various probability distribution functions and the best-fit distribution function is selected by performing various goodness-of-fit tests. The seismic performance of the FA concrete is evaluated by fragility and reliability curves considering the variability in the material properties. The concept of seismic safety evaluation of buildings with partial replacement of FA adds a new dimension to the current research.

\section{EXPERIMENTATION}

One set of control mix with three sets of concrete mixes (with partial replacement of FA) are prepared where the mixture proportions are obtained as per the guidelines of Indian Standard, IS 10262 (2009). As this is a study of the behaviour of concrete incorporating various percentages of fly ash, the mix design is carried out for the control mix only. All the other mixes are obtained by adding various percentages $(20 \%, 40 \%$ and $60 \%)$ of fly ash by weight of total cementitious content. The total cementitious content is taken as a constant which is the cement content in the control mix. Table 1 shows the proportions of cement, FA, natural sand, coarse aggregates, water and admixture by weight of the control mix as well as that of mixes with various percentages of FA dosages. Water content is maintained constant as $177.3 \mathrm{~kg} / \mathrm{m}^{3}$, maximum doses of superplasticizer is kept as $3.5 \%$ of cement weight. Portland Slag Cement, having the 28-day compressive strength of $48 \mathrm{MPa}$ and FA of class F was used for the study. The physical and chemical properties of both cement and FA are given in Table 2 and 3 
respectively. Natural river sand which conforms to Zone-II of IS: 383 (1970) is used as fine aggregates. Water absorption and the specific gravity of fine aggregates are obtained as $0.8 \%$ and 2.65 , respectively. Coarse aggregates used in this study is collected from a local quarry having a maximum size of $20 \mathrm{~mm}$ with the water absorption and specific gravity of $0.6 \%$ and 2.75 , respectively. Test specimens (Cube size: 100mm x 100mm x 100mm, Cylinder size: $100 \mathrm{~mm}$ x 200mm, Prism size: 100mm x 100mm x 500mm) are casted in a weather condition where the ambient temperature range is maintained about $210 \mathrm{C}$ to $450 \mathrm{C}$ and humidity range was about $47 \%$ to $63 \%$. The specimens were cured in a water filled tank located near laboratory.

\section{Variation in Mechanical Properties}

A total of 90 concrete cubes ( 3 mixes with 30 samples for each mix) with various proportions of FA was tested for the compressive strength and presented in Table 4. The control specimen shows a varying compressive strength of 24.18 - 34.60 MPa with a mean and Standard Deviation (SD) of 30.37 and 2.71 respectively. The minimum, maximum, mean and $\mathrm{SD}$ of other concrete specimens with varying proportions of FA are also tabulated here. It was observed that, the mean compressive strength of concrete increases with FA content and attains a peak of $34.63 \mathrm{MPa}$. It can be observed from the table that; the SD of compressive strength is inversely proportional to the FA content and which may be for the high inherent variability in the properties of FA. The observed mean compressive strength of concrete is shown in Fig. 1 for each of the FA dosage.

Flexural strength of FA concrete was tested for 90 concrete cubes and the output is tabulated in Table 4. The control specimen shows a varying flexural strength of 5.63-6.82 MPa with a mean and SD of 6.32 and 0.33 respectively. The minimum, maximum, mean and SD of other concrete specimens with varying proportions of FA are also tabulated here. It was observed that, at $20 \%$ of FA content, the mean compressive strength of FA concrete rises with FA content and attains a peak of 6.36 MPa. The SD of flexural strength is found to be inversely proportional to the FA content and which may be due to the high inherent variability in the properties of FA. The observed mean flexural strength of concrete is shown in Fig. 2 for each level of FA dosage. 
Similarly, the split tensile strength test for FA concrete was carried out for 90 samples and results are tabulated in Table 4. The control specimen shows a varying split tensile strength ranging from $2.18-2.90$ $\mathrm{MPa}$ with a mean and SD of 2.60 and 0.23 respectively. It was observed that the mean split tensile strength of concrete increases with FA content and attains a maximum value of $2.48 \mathrm{MPa}$. The SD of split tensile strength is found to be inversely proportional to the FA content and which may be due to the high inherent variability in the properties of FA. The observed mean split tensile strength of concrete is shown in Fig. 3 for each of the FA dosage. 


\section{Development of Variability Models}

The FA concrete buildings need to be designed and analyzed using a probabilistic approach in order to estimate its seismic performance accurately. The variability in the mechanical properties of FA concrete is described with different probability distribution models as presented in this section. The standard probability distribution models like truncated normal, lognormal, gamma and Weibull distributions are selected for the analysis. Out of the considered models, the model that gives the optimum result is chosen by performing certain goodness-of-fit tests. The tests like Kolmogorov-Smirnov (KS), Log-likelihood (LK) and Chi-square criterion (CS) at a 5\% significance level are performed. The probability distribution with minimal KS distance and CS value and with maximum LK are considered as the best fit which has been successfully validated by Chen et al. (2013) and Stone et al. (1986).

While conducting goodness-of-fit test, if there is any ambiguity between the results of three tests then, priority is given to KS and LK tests. This is because CS test is affected by binning of data in to different class intervals and its suitability is best shown when a large number of random variables are considered. Tables 5, 6 and 7 represent the different distributions for compressive strength, flexural strength, and split tensile strength, respectively. In the same way, cumulative probability distributions are made from the experimental data and compared with assumed distribution functions as shown in Figs. 4-6.

\section{Statistical inference for the mechanical properties of FA concrete}

The shape and scale parameters of distributions (KS distances, LK and CS values) for compressive strength of FA concrete are shown in Table 5 and it can be observed that all three criteria (KS, CS, and LK) are not in agreement with a single distribution for describing the compressive strength of concrete expect the case of $40 \%$ FA concrete. However, minimal deviances among the goodness-of-fit test values for all the mixes are observed. $40 \%$ replacement of FA is found to be satisfying all the selection criteria for minimum KS distance, minimum CS and maximum LK where lognormal distribution is the best fit model for the mix with $20 \%$ and $60 \%$ FA replacement. Fig. 4 shows the probability distributions obtained experimentally and statistically using cumulative probability distribution models for the compressive strength of FA concrete. 
Flexural test results (Table 6) of FA concrete shows that all three testing criteria (KS, CS, and LK) possess minimal deviations among the goodness-of-fit test values for all the mixes. Weibull distribution meets the KS and CS selecting criteria for the mix with 20\% FA and 60\% FA mix fits the gamma distribution. Fig. 5 represents the variation in the cumulative probability distribution of flexural strength for different mix proportions.

Similarly, the assessed shape and scale parameters of distributions (KS distances, LK and CS values) for split tensile strength of FA concrete (Table 7) shows that all three criteria (KS, CS, and LK) are not in agreement with a single distribution for describing the split tensile strength of concrete. The lognormal distribution is found to be satisfying the selection criteria considering KS and LK for $20 \%$ FA replacement. Normal and Weibull distributions are found to be the best fitting for $40 \%$ and $60 \%$ FA replacement, respectively. The cumulative probability distribution models for the split tensile strength of the FA concrete mix are presented in Fig. 6. The probabilistic distribution functions with associated mechanical parameters are tabulated in table 8 and it is clear that the Log-normal distribution and the Weibull distribution functions describe the variability in the mechanical properties of fly ash concrete most accurately.

\section{SEISMIC FRAGILITY CURVES AND PROBABILITY DISTRIBUTION MODEL}

The probability distribution of the mechanical properties of FA concrete can be accurately established through the seismic fragility curves and the reliability indices during the building performance evaluation. The present study uses a simplified approach suggested by Ellingwood (2001) for the development of the fragility curve.

The seismic hazard curve, $G_{A}(x)$, is a plot of $P[A=a]$ and the ground acceleration intensity $(a)$. The target limit state probabilities for a series of progressively severe stages, $L S_{i}$, as follows;

$$
P\left[L S_{i}\right]=\sum_{a} P\left[L S_{i} \mid A=a\right] P[A=a]
$$

In the above expression, the associated uncertainty is mentioned as the fragility function, $F_{R}(x)$ and found to be in an agreement with a two-parameter lognormal probability distribution supported by previous 
studies (Song and Ellingwood 1999, Cornell et. al. 2002, Haran 2014 and Haran et. al. 2015). The point estimate of $L S_{i}$ of the state $i$ can be estimated by uniting the $F_{R}(x)$ with the derivative of $G_{A}(x)$, thus eliminating the acceleration state,

$$
P\left[L S_{i}\right]=\int F_{R}(x) \frac{d G_{A}}{d x} d x
$$

The reliability index conforming to the failure probability can be estimated by the following standard equation;

$$
\beta_{P f}=-\phi^{-1}\left(P\left[L S_{i}\right]\right)
$$

Where $\phi$ ( ) represents the standard normal distribution.

A linear relationship was observed between the annual probability of occurrence and the spectral acceleration at moderate to large ground accelerations and the hazard function, $G A(a)$, which is expressed as follows;

$$
G_{A}(x)=1-\exp \left[-(x / u)^{-k}\right]
$$

where $u$ and $k$ are the parameters of the distribution.

Nath and Thingbaijam (2012), Pallav et al. (2012), Raju et al. (2012) and Sitharam et al. (2015) have developed the seismic hazard map for India. Iyengar et al. (2010) and Dhir et al. (2018) have used the data available at National Disaster Management Authority to develop the seismic hazard curves for the seismic hazard analysis. Imphal, being one of the most vulnerable places of seismic zone-V of Indian seismic hazard map is considered in the present study (Fig. 7).

\section{Selected Frame}

A typical four-storey-two-bay RC bare frame with a symmetric plan and elevation is selected (Fig. 8). This building is designed as per IS 456 (2000) considering the for seismic forces corresponding to the highest seismic zone V (PGA of $0.36 \mathrm{~g}$ ) as per IS 1893 (2002) and considering medium soil conditions (N-value in the range 10-30). The characteristic strength of concrete and steel are taken as $25 \mathrm{MPa}$ and 
$415 \mathrm{MPa}$, respectively. A dead load of slab was calculated to be $0.00375 \mathrm{MPa}$ on which a live load of $0.003 \mathrm{MPa}$ was considered. $230 \mathrm{~mm}$ thick brick walls are considered and applied separately as a uniformly distributed load on beams.

In order to represent the different practical conditions, different building models are chosen with varying proportions of FA and the associated variability with the strength properties of concrete was observed. The selected building frame is designated with a standard name as XY, where X denotes ' $F A$ ' for fly ash and the percentage of replacement of FA is denoted by Y. The design details of the selected frame are shown in Table 9.

\section{Structural Modelling}

Selected buildings are modeled for nonlinear time history analysis needed for the seismic risk assessment. The Open System for Earthquake Engineering Simulation (OpenSEES) Laboratory tool developed by McKenna et al. (2014) is considered for all the analysis. A force-based nonlinear beam-column fiber element that considers the spread of plasticity along the element is used for modeling the beams and columns. The formulation of the force-based fiber element is explained in Lee and Mosalam (2004). Kunnath (2007) shows the sensitivity due to the number of integration points in each element and suggest the use of five integration points for fiber elements, which is considered in the present study. The modeling of the core concrete performed by bearing in mind the influence of the special reinforcement detailing in the beams and columns as suggested by Kent and Park (1971) and the cover concrete is modeled as unconfined concrete. Steel rebars are modelled as per Giuffre-Menegotto-Pinto steel material model and the details of reinforcement modeling are available in Filippou et al. (1983).

A lumped mass approach is taken into account where both the dead loads and the live loads (25\%) are considered and the Rigid diaphragm constraints are used for the floor slab in-plane stiffness modelling. The Raleigh damping model is used for dynamic analysis as reported by Filippou et al. (1992). 44 ground motions are taken into consideration (Haselton et al. 2012). During the non-linear analysis, the converted ground motions are further matched with IS 1893 (BIS 2002) design spectrum using a computer program 
(Mukherjee and Gupta 2002). Uncertainties in concrete compressive strength, reinforcing steel yield strength, and global damping ratio are considered during the seismic performance study. Table 10 shows the mean and coefficient of variation $(\mathrm{COV})$ of the normal probability distributions of the previous parameters are obtained from published literature. Details of random variables used are available in Dhir et al. (2018).

\section{Seismic Fragility Curves}

The exceedance probability of Inter Storey Drift $(I S D)$ can be presented by a fragility function, $F_{R}(x)$ for a selected structural limit state $(L S)$ at a specific Peak Ground Acceleration $(P G A)$;

$$
P(D \geq C \mid \mathrm{PGA})=\varphi\left(\frac{\ln \frac{S_{D}}{S_{C}}}{\sqrt{\beta_{D \mid \mathrm{PGA}}^{2}+\beta_{c}^{2}}}\right)
$$

where $C$ is the drift capacity at a selected limit state, $D$ is the drift demand, $S_{C}$ is the median of the chosen limit state $(L S), S_{D}$ is the median of the drift demand. $\beta_{c}$ and $\beta_{d / P G A}$ are dispersions in the capacities and the $P G A$ respectively. The building type and the construction quality significantly influence the magnitude of $\beta_{c}$. The values of $\beta_{c}$ are $0.10,0.25$ and 0.40 for good, fair and poor quality of construction respectively (ATC 58 2012) and selected as 0.25 in this study. Nielson et. al. (2005), Davis et. al. (2010b), Rajeev and Tesfamariam (2012), Bhosale (2017, 2018), Dhir et al. (2018, 2020), Mistri et al. 2019, Sahu et al. (2019) and Sahoo et al. (2020) have developed the seismic fragility curves of RC frames using the above methodology.

The PSDMs are developed, and presented using Peak ground Acceleration (PGA) for the nonlinear analysis. Cornell et.al (2002) estimated the median demand, ISD $\left(S_{D}\right)$ by a generalized equation as follows.

$$
I S D=a(P G A)^{b}
$$

Where $a$ and $b$ are the regression coefficients from PSDMs. 


\section{Selected Performance limit states}

The different level of damage sustainability of any structure has always been the representative of its structural limit states. The median inter-storey drift limits for RC moment-resisting structures at various

performance levels $\left(S_{C}\right)$ are suggested by Ghobarah (2000) and ASCE/SEI 41-06 (2007). In the present study, $2 \%$ and $4 \%$ of drift limits are considered for RC frames representing significant damage (SD) and collapse prevention (CP) as suggested by ASCE/SEI 41-06 (2007).

\section{Material uncertainty}

Compressive strength of concrete and steel, and the global damping ratio are the most sensitive variables considered as random and Table 11 shows the mean and standard deviations of these selected variables. A set of 44 numbers of computational models is produced using the Latin Hypercube sampling technique for the nonlinear dynamic analysis. 


\section{PSDMs for all selected frames}

The 44 computational models were generated using 44 numbers of earthquake ground motions scaled from $0.1 \mathrm{~g}$ to $1.0 \mathrm{~g}$ for a particular randomly selected PGA. The maximum inter-storey drifts are plotted on a logarithmic scale for the buildings modeled with FA concrete (Fig. 9). The regression analysis is performed and a power law relationship (Eq. 6) is established for each of the frame during the development of PSDM. The regression coefficients ( $a$ and $b$ ) of the PSDMs are tabulated in Table 12. It can be observed that the higher the value of inter-storey drift, the higher will be the vulnerability of the building.

\section{Fragility Curves}

The developed Fragility curves for all selected frames at selected performance limit states are presented in Fig. 10. The fragility curves for SD and CP performance levels are shown in Figs. 10(a) and 10(b) respectively. It can be observed that, the seismic performance of frames with $20 \%$ partial replacement of FA are found to be performing better than the other frames and frames having $60 \%$ replacement of FA are more vulnerable than the frame with normal concrete.

\section{Comparison of reliability indices}

The estimated reliability indices give a better understanding of the performance of all the selected frames quantitatively. The site seismic hazard curve of Imphal located in the North East region of India was chosen for the estimation of reliability. PO-I and PO-II are the two performance objectives selected against the structural capacity where, PO-I represents the Significant Damage (SD) state performance limit at an earthquake occurrence probability of $10 \%$ in 50 years and PO-II represents the Collapse Prevention $(\mathrm{CP})$ stage where the earthquake occurrence probability is $2 \%$ in 50 years. From the selected hazard curve (Fig.7), PGAs corresponding to the $10 \%$ and $2 \%$ probability of occurrence are obtained as $0.67 \mathrm{~g}$ and $1.35 \mathrm{~g}$ respectively. The reliability indices for the FA concrete frames for selected performance limits are presented in Fig. 11. Similarly, the calculated reliability indices for the selected frames at PO-I and PO-II performance objectives are tabulated in Table 13. FA20 is found to be having the highest 
reliability index values at PO-I and PO-II for the selected building frame. It was observed that 20-40\% partial replacement of FA may be appropriate for attending the better seismic performance. 


\section{SUMMARY AND CONCLUSIONS}

In order to describe the variability in the mechanical properties of FA concrete, a statistical analysis was performed taking the experimental outcomes with a two-parameter probability function. Several distributions are selected to describe the experimental data closely by establishing the best-fit models for compressive strength (Table 14), flexural strength (Table 15) and split tensile strength (Table 16) of FA concrete as reported in the Appendix. Statistical distributions with the most accurate prediction are proposed for the selected parameters. KS, CS, and LK, the three selected statistical criteria are not always in agreement with some concrete mixes with a single distribution. In this case, the closest fit model is chosen as per the KS distance and the LK value (Chen et al. 2013). The present study suggests the use of lognormal distribution function as the distribution model as it most closely describes the variations associated with the mechanical properties of FA concrete. The performance of the selected building frames using FA concrete is evaluated using fragility curves and reliability indices and it was observed that $20-40 \%$ partial replacement of FA may amplify the performance of the structure.

It is also to be noted that the present study does not account for the variability of the concrete incorporating FA in a realistic practical construction situation. The mix proportions of concrete used in such a practical industrial construction may have variability due to raw materials obtained from different sources, fly ash from different sources, variability due to different weather conditions, differences in workmanships, difference in mix designs etc. On the other hand, the present study conducts all the experiments in an ideal laboratory environment, casting of the cubes are all carried out almost in the same climatic conditions and time, the sources of the raw materials used for the concrete are all from the same sources. The variability of the resulting fly ash concrete in the present study is assumed due to the change in different dosages of fly ash. Hence the variability information attempted here can be treated at the lower bound by the results expected from a comprehensive study mentioned above. Hence, the present study is limited, however, in the absence of such an exhaustive comprehensive study, the variability results obtained in the present study can be treated at the lower bound of the expected variability.

\section{DATA AVAILABILITY STATEMENT}


Some data, models, or code generated or used during the study are available from the corresponding author by request (OpenSEES modeling files and generated outputs) 


\section{REFERENCES}

Applied Technology Council (ATC-58). (2007). Guidelines for Seismic Performance Assessment of Buildings.

ASCE/SEI Seismic Rehabilitation Standards Committee. (2007). Seismic rehabilitation of existing buildings (ASCE/SEI 41-06). American Society of Civil Engineers, Reston, VA.

Bhosale, A. S., Davis, R., \& Sarkar, P. (2017). Vertical irregularity of buildings: Regularity index versus seismic risk. ASCE-ASME Journal of Risk and Uncertainty in Engineering Systems, Part A: Civil Engineering, 3(3), 04017001.

Bhosale, A. S., Davis, R., \& Sarkar, P. (2018). Seismic Safety of Vertically Irregular Buildings: Performance of Existing Indicators. Journal of Architectural Engineering, 24(3), 04018013.

BIS (Bureau of Indian Standards) 3812 (Part 1). (2003). Indian standard pulverized fuel ash-Specification. Bureau of Indian Standards. New Delhi, India.

BIS (Bureau of Indian Standards). (2002). "Criteria for earthquake resistant design of structures. Part 1: General provisions and buildings.” IS-1893, Bureau of Indian Standards. New Delhi, India.

BIS (Bureau of Indian Standards). IS 10262 (2009). Indian Standard Recommended guidelines for concrete mix design, Bureau of Indian Standards. New Delhi, India.

BIS (Bureau of Indian Standards). IS 383 (1970). Indian Standard Specification for Coarse and Fine Aggregates from Natural Sources for Concrete, Bureau of Indian Standards. New Delhi, India.

BIS (Bureau of Indian Standards). IS 383. (1970). Specification for coarse and fine aggregates from natural sources for concrete. Bureau of Indian Standards. New Delhi, India.

BIS (Bureau of Indian Standards). IS 455 (1989). Indian Standard Portland Slag Cement - Specification, Bureau of Indian Standards, New Delhi. 
BIS, I. (2000). 456 (2000) Plain and reinforced Concrete-Code of Practice. Bureau of Indian Standards, New Delhi, India.

Campbell, R. H., \& Tobin, R. E. (1967, April). Core and cylinder strengths of natural and lightweight concrete. In Journal Proceedings (Vol. 64, No. 4, pp. 190-195).

Celik, O. C., \& Ellingwood, B. R. (2009). Seismic risk assessment of gravity load designed reinforced concrete frames subjected to Mid-America ground motions. Journal of Structural Engineering, 135(4).

Chen, X., Wu, S., \& Zhou, J. (2013). Variability of compressive strength of concrete cores. Journal of Performance of Constructed Facilities, 28(4), 06014001.

Chmielewski, T., \& Konopka, E. (1999). Statistical evaluations of field concrete strength. Magazine of concrete research, 51(1), 45-52.

Cornell, C. A., Jalayer, F., Hamburger, R. O., \& Foutch, D. A. (2001). The probabilistic basis for the 2000 SAC/FEMA steel moment frame guidelines. Submitted to. J. Struct. Engrg.

Davis, P. R., Padhy, K. T., Menon, D., \& Prasad, A. M. (2010, July). Seismic fragility of open ground storey buildings in India. In the 9th US National and 10th Canadian Conference on Earthquake Engineering.

Dhir, P. K., Davis, R., \& Sarkar, P. (2018). Safety Assessment of Gravity Load-Designed Reinforced Concrete-Framed Buildings. ASCE-ASME Journal of Risk and Uncertainty in Engineering Systems, Part A: Civil Engineering, 4(2), 04018004.

Dhir, P. K., Zade, N. P., Basu, A., Davis, R., \& Sarkar, P. (2020). Implications of Importance Factor on Seismic Design from 2000 SAC-FEMA Perspective. ASCE-ASME Journal of Risk and Uncertainty in Engineering Systems, Part A: Civil Engineering, 6(2), 04020016.

Ellingwood, B. R. (2001). Earthquake risk assessment of building structures. Reliability Engineering \& System Safety, 74(3), 251-262. 
Filippou, F. C., Bertero, V. V., \& Popov, E. P. (1983). Effects of bond deterioration on hysteretic behavior of reinforced concrete joints.

Filippou, F. C., d'Ambrisi, A., \& Issa, A. (1992). Nonlinear static and dynamic analysis of RC subassemblages. Rep. No. UCB/EERC-92, 8 .

Ghobarah, A. (2001). Performance-based design in earthquake engineering: state of development. Engineering structures, 23(8), 878-884.

Graybeal, B., \& Davis, M. (2008). Cylinder or cube: strength testing of 80 to $200 \mathrm{MPa}$ (11.6 to 29 psi) ultra-high-performance fiber-reinforced concrete. Materials Journal, 105(6), 603-609.

Haran, P. D. C. (2014). Reliability based seismic design of open ground storey framed buildings (Doctoral dissertation, Ph. D. thesis, National Institute of Technology Rourkela, Rourkela, Orissa, India).

Haran, P. D. C., Davis, R. P., and Sarkar, P. (2015). "Reliability evaluation of RC frame by two major fragility analysis methods." Asian J. Civ. Eng., 16(1), 47-66.

Haselton, C. B., Whittaker, A. S., Hortacsu, A., Baker, J. W., Bray, J., \& Grant, D. N. (2012, September). Selecting and scaling earthquake ground motions for performing response-history analyses. In Proceedings of the 15th World Conference on Earthquake Engineering.

Iyengar, R. N., Chadha, R. K., Rao, K. B., and Raghukanth, S. T. G. (2010). "Development of probabilistic seismic hazard map of India.” Final Rep., National Disaster Management Authority, New Delhi, India.

Kent, D. C., and Park, R. (1971). “Flexural members with confined concrete.” J. Struct. Div., 97(7), 19691990.

Kunnath, S. K. (2006). Application of the PEER PBEE Methodology to the I-880 Viaduct: I-880 Testbed Committee. Pacific Earthquake Engineering Research (PEER) Center, College of Engineering, University of California. 
Lee, T. H., \& Mosalam, K. M. (2004). Probabilistic fiber element modeling of reinforced concrete structures. Computers \& structures, 82(27), 2285-2299.

McKenna, F., McGann, C., Arduino, P., \& Harmon, J. A. (2013). OpenSEES laboratory.

Mistri, A., Sarkar, P., \& Davis, R. (2019). Column-beam moment capacity ratio and seismic risk of reinforced concrete frame building. Proceedings of the Institution of Civil Engineers-Structures and Buildings, 172(3), 189-196.

Mukherjee, S., \& Gupta, V. K. (2002). Wavelet-based generation of spectrum-compatible time-histories. Soil Dynamics and Earthquake Engineering, 22(9-12), 799-804.

Nath, S. K., \& Thingbaijam, K. K. S. (2012). Probabilistic seismic hazard assessment of India. Seismological Research Letters, 83(1), 135-149.

Nielson, B. G. (2005). Analytical fragility curves for highway bridges in moderate seismic zones (Doctoral dissertation, Georgia Institute of Technology).

Pallav, K., Raghukanth, S.T.G. and Singh, K.D., (2012). Probabilistic seismic hazard estimation of Manipur, India. Journal of geophysics and engineering, 9(5), p.516.

Rajeev, P., \& Tesfamariam, S. (2012). Seismic fragilities for reinforced concrete buildings with consideration of irregularities. Structural Safety, 39, 1-13.

Raju KR, A Cinitha A, Iyer NR. Seismic performance evaluation of existing RC buildings designed as per past codes of practice, Indian Academy of Sciences, 2002: Vol. 37, No. 2, April 2012, pp. 281-297.

Ranganathan, R. (1999). Structural reliability analysis and design. Jaico Publishing House.

Saha, A. K. (2019). A comparative study between ASTM C1567 and ASTM C227 to mitigate alkali-silica reaction. Structural Concrete, 20(1), 420-427. 
Saha, A. K., \&Sarker, P. K. (2020). Effect of sulphate exposure on mortar consisting of ferronickel slag aggregate and supplementary cementitious materials. Journal of Building Engineering, 28, 101012.

Saha, A. K., Khan, M. N. N., Sarker, P. K., Shaikh, F. A., \&Pramanik, A. (2018). The ASR mechanism of reactive aggregates in concrete and its mitigation by fly ash: A critical review. Construction and Building Materials, 171, 743-758.

Saha, A. K., Sarker, P. K., \&Golovanevskiy, V. (2019). Thermal properties and residual strength after high temperature exposure of cement mortar using ferronickel slag aggregate. Construction and Building Materials, 199, 601-612.

Sahoo, K., Dhir, P. K., Teja, P. R. R., Sarkar, P., \& Davis, R. (2020). Variability of silica fume concrete and its effect on seismic safety of reinforced concrete buildings. Journal of Materials in Civil Engineering, 32(4), 04020024.

Sahu, D., Nishanth, M., Dhir, P. K., Sarkar, P., Davis, R., \& Mangalathu, S. (2019). The stochastic response of reinforced concrete buildings using high dimensional model representation. Engineering Structures, 179, 412-422.

Sitharam, T. G., Kolathayar, S., \& James, N. (2015). Probabilistic assessment of surface-level seismic hazard in India using a topographic gradient as a proxy for site condition. Geoscience Frontiers, 6(6), 847-859.

Song, J., \& Ellingwood, B. R. (1999). Seismic reliability of special moment steel frames with welded connections: II. Journal of Structural Engineering, 125(4), 372-384.

Soroka, I. (1968). An application of statistical procedures to quality control of concrete. Materials and Construction, 1 (5), 437-441.

Stone, W. C., Carino, N. J., \& Reeve, C. P. (1986, September). Statistical methods for in-place strength predictions by the pullout test. In Journal Proceedings (Vol. 83, No. 5, pp. 745-756). 

Table 1. Considered material proportions

\begin{tabular}{lcccc}
\hline \multicolumn{1}{c}{ Mixture name } & Control & $20 \%$ FA & $40 \%$ FA & $60 \%$ FA \\
\hline Cement $\left(\mathrm{kg} / \mathrm{m}^{3}\right)$ & 394 & 315.20 & 236.4 & 157.60 \\
\hline FA $\left(\mathrm{kg} / \mathrm{m}^{3}\right)$ & - & 78.80 & 157.60 & 236.40 \\
\hline Natural sand $\left(\mathrm{kg} / \mathrm{m}^{3}\right)$ & 641 & 641 & 641 & 641 \\
\hline Coarse aggregate $\left(\mathrm{kg} / \mathrm{m}^{3}\right)$ & 1114 & 1114 & 1114 & 1114 \\
\hline$w / c$ & 0.450 & 0.450 & 0.450 & 0.450 \\
\hline Water $\left(\mathrm{kg} / \mathrm{m}^{3}\right)$ & 177.3 & 177.30 & 177.30 & 177.30 \\
\hline Admixture $\left(\mathrm{kg} / \mathrm{m}^{3}\right)$ & 1.970 & 2.760 & 3.150 & 3.550 \\
\hline
\end{tabular}

$*$ Conversion factor $\mathrm{kg} / \mathrm{m}^{3}=$ multiply by $0.062428 \mathrm{lb} / \mathrm{ft}^{3}$

Table 2. Physical and chemical properties of Portland Slag Cement

\begin{tabular}{|l|c|c|}
\hline Properties & $\begin{array}{l}\text { Test } \\
\text { Results }\end{array}$ & $\begin{array}{l}\text { Requirement as } \\
\text { per IS:455-1989 }\end{array}$ \\
\hline \multicolumn{2}{|c|}{ Physical Requirements } \\
\hline $\begin{array}{l}\text { Specific Surface (blane) } \\
\mathrm{m}^{2} / \mathrm{kg}\end{array}$ & 343 & 225 (Minimum) \\
\hline Specific Gravity & 3.01 & \\
\hline \multicolumn{2}{|c|}{ Chemical Requirements } \\
\hline Insoluble Residue (\% by mass) & 2.0 & 4.0 (Maximum) \\
\hline $\mathrm{MgO}_{\%}$ (by mass) & 6.7 & 10.0 (Maximum) \\
\hline $\mathrm{SO}_{3} \%$ (by mass) & 1.8 & 3.0 (Maximum) \\
\hline $\mathrm{S} \%$ (by mass) & 0.2 & 1.5 (Maximum) \\
\hline
\end{tabular}

Table 3. Physical and chemical requirements of FA

\begin{tabular}{|c|c|c|}
\hline Parameter & Test Results & $\begin{array}{l}\text { Requirement as per IS } 3812 \\
(\text { Part1 }): 2003\end{array}$ \\
\hline \multicolumn{3}{|l|}{ Physical Requirements } \\
\hline $\begin{array}{l}\text { Fineness-Specific surface in } \\
\mathrm{m}^{2} / \mathrm{kg}\end{array}$ & 329 & 320.00 (Minimum) \\
\hline$>45$ Micron $(\%)$ & 2.72 & 34.0 (Maximum) \\
\hline \multicolumn{3}{|l|}{ Chemical Requirements } \\
\hline $\mathrm{SiO}_{2}(\%)$ & 39.88 & 35.00 (Minimum) \\
\hline $\mathrm{MgO}$ & 1.15 & 5.00 (Maximum) \\
\hline
\end{tabular}


Table 4. Mechanical properties of FA Concrete

\begin{tabular}{llllllllll}
\hline \multirow{2}{*}{ Specimen } & \multicolumn{2}{l}{$\begin{array}{l}\text { Compressive } \\
(\mathrm{MPa})\end{array}$} & Strength & \multicolumn{2}{c}{ Flexural Strength (MPa) } & $\begin{array}{l}\text { Tensile } \\
(\mathrm{MPa})\end{array}$ & Splitting & Strength \\
\cline { 2 - 10 } & Mean & SD & Range & Mean & SD & Range & Mean & SD & Range \\
\hline Control & 30.37 & 2.71 & $\begin{array}{l}24.18-3 \\
4.60\end{array}$ & 6.32 & 0.33 & $\begin{array}{l}5.63-6 . \\
82\end{array}$ & 2.60 & 0.23 & $\begin{array}{l}2.18-2 . \\
90\end{array}$ \\
\hline $20 \%$ FA & 34.63 & 1.15 & $\begin{array}{l}32.28-3 \\
6.95\end{array}$ & 6.36 & 0.48 & $\begin{array}{l}5.51-7 . \\
15\end{array}$ & 2.48 & 0.35 & $\begin{array}{l}1.98-3 . \\
13\end{array}$ \\
\hline $40 \%$ FA & 28.48 & 1.50 & $\begin{array}{l}25.4-31 \\
.14\end{array}$ & 4.53 & 0.34 & $\begin{array}{l}3.94-5 . \\
07\end{array}$ & 1.79 & 0.06 & $\begin{array}{l}1.66-1 . \\
89\end{array}$ \\
\hline $60 \%$ FA & 14.79 & 0.93 & $\begin{array}{l}13.37-1 \\
6.48\end{array}$ & 3.33 & 0.18 & $\begin{array}{l}2.90-3 . \\
68\end{array}$ & 1.37 & 0.09 & $\begin{array}{l}1.17-1 . \\
52\end{array}$ \\
\hline
\end{tabular}

Table 5. Shape and scale parameters for evaluating the compressive strength

\begin{tabular}{llccccc}
\hline Mix Name & Distribution & Shape & Scale & KS & CS & LK \\
\hline \multirow{3}{*}{ Control } & Weibull & 13.49 & 31.57 & 0.07 & 0.64 & -71.49 \\
\cline { 2 - 7 } & Gamma & 125.85 & 0.24 & 0.07 & 0.88 & -72.37 \\
\cline { 2 - 7 } & Normal & 30.37 & 2.71 & 0.06 & 0.71 & -72.05 \\
\cline { 2 - 7 } & Lognormal & 0.09 & 30.23 & 0.07 & 0.76 & -72.58 \\
\hline \multirow{3}{*}{$20 \%$ FA } & Weibull & 32.25 & 35.18 & 0.20 & 5.36 & -47.99 \\
\cline { 2 - 7 } & Gamma & 939.47 & 0.03 & 0.16 & 4.59 & -46.23 \\
\cline { 2 - 7 } & Normal & 34.63 & 1.15 & 0.15 & 4.74 & -46.26 \\
\hline \multirow{3}{*}{$40 \%$ FA } & Log Normal & 0.03 & 3.54 & 0.15 & 4.67 & -46.21 \\
\cline { 2 - 7 } & Weibull & 20.82 & 29.19 & 0.17 & 3.88 & -55.55 \\
\cline { 2 - 7 } & Gamma & 370.59 & 0.07 & 0.12 & 4.16 & -54.29 \\
\hline & Normal & 28.48 & 1.50 & 0.12 & 4.00 & -54.34 \\
\hline \multirow{3}{*}{$60 \%$ FA } & Log Normal & 0.05 & 3.34 & 0.12 & 3.88 & -54.30 \\
\cline { 2 - 7 } & Weibull & 15.23 & 17.11 & 0.13 & 0.71 & -41.52 \\
\cline { 2 - 7 } & Gamma & 259.88 & 0.05 & 0.10 & 1.10 & -39.95 \\
\hline & Lormal & 14.79 & 0.93 & 0.09 & 0.97 & -40.04 \\
\hline
\end{tabular}


Table 6 Shape and scale parameters for evaluating the flexural strength

\begin{tabular}{llccccc}
\hline Mix Name & Distribution & Shape & Scale & KS & CS & LK \\
\hline \multirow{3}{*}{ Control } & Weibull & 22.70 & 6.47 & 0.14 & - & -5.76 \\
\cline { 2 - 7 } & Gamma & 374.40 & 0.01 & 0.10 & - & -6.00 \\
\cline { 2 - 7 } & Normal & 6.32 & 0.33 & 0.10 & - & -5.91 \\
\cline { 2 - 7 } & Lognormal & 0.05 & 6.29 & 0.09 & - & -6.07 \\
\hline \multirow{3}{*}{$20 \%$ FA } & Weibull & 6.58 & 14.87 & 0.10 & 2.81 & -21.07 \\
\cline { 2 - 7 } & Gamma & 173.66 & 0.036 & 0.12 & 4.6 & -20.65 \\
\cline { 2 - 7 } & Normal & 6.36 & 0.48 & 0.11 & 4.19 & -20.61 \\
\cline { 2 - 6 } & Log Normal & 0.07 & 1.84 & 0.12 & 4.47 & -20.71 \\
\hline \multirow{3}{*}{$40 \%$ FA } & Weibull & 4.69 & 15.09 & 0.18 & 0.37 & -10.44 \\
\cline { 2 - 6 } & Gamma & 183.06 & 0.02 & 0.17 & 1.31 & -9.72 \\
\cline { 2 - 6 } & Normal & 4.53 & 0.34 & 0.16 & 1.03 & -9.75 \\
\cline { 2 - 6 } & Log Normal & 0.07 & 1.50 & 0.16 & 1.22 & -9.74 \\
\hline \multirow{3}{*}{$60 \%$ FA } & Weibull & 3.38 & 20.21 & 0.08 & 1.64 & -8.16 \\
\cline { 2 - 6 } & Gamma & 326.64 & 0.01 & 0.07 & 1.49 & -8.46 \\
\cline { 2 - 6 } & Normal & 3.30 & 0.18 & 0.07 & 1.44 & -8.60 \\
\hline & Log Normal & 0.05 & 1.19 & 0.07 & 1.63 & -8.36 \\
\hline
\end{tabular}

Table 7. Shape and scale parameters for evaluating the split tensile strength

\begin{tabular}{|c|c|c|c|c|c|c|}
\hline Mix Name & Distribution & Shape & Scale & KS & $\mathrm{CS}$ & LK \\
\hline \multirow{4}{*}{ Control } & Weibull & 13.59 & 2.70 & 0.10 & - & -1.45 \\
\hline & Gamma & 123.06 & 0.21 & 0.11 & - & -0.65 \\
\hline & Normal & 2.60 & 0.23 & 0.10 & - & -0.87 \\
\hline & Lognormal & 0.09 & 2.58 & 0.10 & - & -0.50 \\
\hline \multirow{4}{*}{$20 \%$ FA } & Weibull & 2.64 & 7.62 & 0.15 & 1.81 & -12.27 \\
\hline & Gamma & 50.5 & 0.04 & 0.15 & 1.28 & -10.82 \\
\hline & Normal & 2.48 & 0.35 & 0.15 & 1.34 & -11.24 \\
\hline & Log Normal & 0.14 & 0.89 & 0.14 & 1.04 & -10.70 \\
\hline \multirow{4}{*}{$40 \% \mathrm{FA}$} & Weibull & 1.82 & 32.86 & 0.14 & 0.61 & -40.51 \\
\hline & Gamma & 823.22 & 0.02 & 0.16 & 1.03 & -39.83 \\
\hline & Normal & 1.79 & 0.06 & 0.08 & 0.92 & -40.63 \\
\hline & Log Normal & 0.03 & 0.58 & 0.08 & 0.95 & -40.49 \\
\hline \multirow{4}{*}{$60 \% \mathrm{FA}$} & Weibull & 1.42 & 18.03 & 0.09 & 2.46 & -29.91 \\
\hline & Gamma & 221.50 & 0.00 & 0.14 & 3.73 & -28.76 \\
\hline & Normal & 1.37 & 0.09 & 0.11 & 3.18 & -29.11 \\
\hline & Log Normal & 0.06 & 0.31 & 0.11 & 3.27 & -28.64 \\
\hline
\end{tabular}


Table 8. Most appropriate statistical distribution functions for the mechanical properties of FA Concrete

\begin{tabular}{cccc}
\hline $\begin{array}{c}\text { FA content in } \\
\text { concrete }(\%)\end{array}$ & compressive strength & flexural strength & split tensile strength \\
\hline 0 & Weibull & Lognormal & Lognormal \\
\hline 20 & Lognormal & Weibull & Lognormal \\
\hline 40 & Lognormal & Lognormal & Normal \\
\hline 60 & Lognormal & Gamma & Weibull \\
\hline
\end{tabular}

Table 9. The design and detailing of the frames

\begin{tabular}{cccccc}
\hline Members & $\begin{array}{c}\text { Floor no./ } \\
\text { Storey no. }\end{array}$ & $\begin{array}{c}\text { Width } \\
(\mathrm{mm})\end{array}$ & $\begin{array}{c}\text { Depth } \\
(\mathrm{mm})\end{array}$ & \multicolumn{2}{c}{ Reinforcement type } \\
\hline Beam & 1 to 3 & 300 & 450 & $\begin{array}{c}\text { Longitudinal } \\
{[5-250 \varphi](\text { Top })+}\end{array}$ & Transverse \\
\hline Beam & 4 & 300 & 450 & $\begin{array}{c}{[5-250 \varphi](\text { Bottom })} \\
{[4-16 \varphi] \text { (Bottom) }}\end{array}$ & $10 \varphi$ @ $100 \mathrm{c} / \mathrm{c}$ \\
\hline Column & $1-4$ & 350 & 350 & $\begin{array}{c}8-25 \varphi(\text { Uniformly } \\
\text { distributed })\end{array}$ & $100 \mathrm{c} / \mathrm{c}$ \\
\hline
\end{tabular}

Table 10: Description of selected random variables

\begin{tabular}{ccccc}
\hline Random variables & Mean & COV $(\%)$ & $\begin{array}{c}\text { Probability } \\
\text { Distribution }\end{array}$ & Source \\
\hline $\begin{array}{c}\text { Concrete compressive } \\
\text { strength }\end{array}$ & $33.66 \mathrm{MPa}$ & 21.0 & Normal & Ranganathan (1999) \\
\hline Steel yield strength & $483.47 \mathrm{MPa}$ & 10.0 & Normal & Ranganathan (1999) \\
\hline Global damping ratio & $5 \%$ & 76.0 & Lognormal & $\begin{array}{c}\text { Celik and } \\
\text { Ellingwood (2009) }\end{array}$ \\
\hline
\end{tabular}

Table 11. Concrete compressive strength of selected building types

\begin{tabular}{cccc}
\hline Frame ID & Mean (MPa) & C.O.V $(\%)$ & $\begin{array}{c}\text { Distribution } \\
\text { function }\end{array}$ \\
\hline C & 30.28 & 8.94 & Lognormal \\
\hline FA20 & 34.63 & 3.32 & Lognormal \\
\hline FA40 & 28.48 & 5.26 & Lognormal \\
\hline FA60 & 14.79 & 6.28 & Lognormal \\
\hline
\end{tabular}

Table: 12. Regression output of PSDM for control and FA concrete buildings

\begin{tabular}{cccc}
\hline Frame ID & $a(P G A)^{b}$ & $a$ & $b$ \\
\hline C & $2.58(P G A)^{0.620}$ & 2.58 & 0.62 \\
\hline FA20 & $2.34(P G A)^{0.620}$ & 2.34 & 0.62 \\
\hline FA40 & $2.95(P G A)^{0.720}$ & 2.95 & 0.72 \\
\hline FA60 & $5.32(P G A)^{0.840}$ & 5.32 & 0.84 \\
\hline
\end{tabular}


Table 13. Reliability Index $\left(P_{f}\right)$ for control and FA concrete

\begin{tabular}{lcc} 
Frame ID & PO-I & PO-II \\
$\beta_{P f}\left(\mathrm{P}_{\mathrm{f}}\right)$ & $\beta_{P f}\left(\mathrm{P}_{\mathrm{f}}\right)$ \\
\hline C & $1.07(1.42 \mathrm{E}-01)$ & $1.76(3.92 \mathrm{E}-02)$ \\
\hline FA20 & $1.33(9.17 \mathrm{E}-02)$ & $2.06(1.97 \mathrm{E}-02)$ \\
\hline FA40 & $1.07(1.42 \mathrm{E}-01)$ & $1.76(3.92 \mathrm{E}-02)$ \\
\hline FA60 & $1.08(1.40 \mathrm{E}-01)$ & $1.69(4.55 \mathrm{E}-02)$ \\
\hline
\end{tabular}

\section{Appendix. Mechanical Properties of FA Concrete}

Table 14. compressive strength of FA concrete (in MPa)

\begin{tabular}{|c|c|c|c|c|}
\hline Sl. No. & Control & $\begin{array}{c}20 \% \\
\text { replacement } \\
\text { by FA }\end{array}$ & $\begin{array}{c}40 \% \\
\text { replacement } \\
\text { by FA }\end{array}$ & $\begin{array}{c}60 \% \\
\text { replacement } \\
\text { by FA }\end{array}$ \\
\hline 1 & 24.18 & 32.28 & 25.40 & 13.37 \\
\hline 2 & 26.23 & 32.88 & 26.40 & 13.37 \\
\hline 3 & 26.66 & 33.29 & 26.50 & 13.43 \\
\hline 4 & 26.76 & 33.29 & 26.50 & 13.43 \\
\hline 5 & 27.26 & 33.58 & 27.16 & 13.75 \\
\hline 6 & 27.41 & 33.60 & 27.16 & 13.90 \\
\hline 7 & 27.81 & 33.67 & 27.28 & 13.91 \\
\hline 8 & 28.54 & 33.67 & 27.28 & 13.97 \\
\hline 9 & 28.64 & 34.01 & 27.71 & 14.12 \\
\hline 10 & 28.84 & 34.01 & 27.71 & 14.12 \\
\hline 11 & 29.21 & 34.02 & 27.81 & 14.25 \\
\hline 12 & 29.72 & 34.30 & 27.97 & 14.79 \\
\hline 13 & 29.83 & 34.31 & 27.98 & 14.80 \\
\hline 14 & 30.22 & 34.43 & 27.98 & 14.8 \\
\hline 15 & 30.51 & 34.45 & 28.21 & 14.86 \\
\hline 16 & 30.98 & 34.54 & 28.24 & 14.86 \\
\hline 17 & 31.17 & 34.56 & 28.25 & 14.88 \\
\hline 18 & 31.34 & 34.65 & 28.49 & 14.94 \\
\hline 19 & 31.52 & 34.66 & 28.74 & 15.13 \\
\hline 20 & 31.56 & 34.66 & 28.85 & 15.13 \\
\hline 21 & 31.82 & 35.67 & 29.89 & 15.22 \\
\hline 22 & 32.57 & 35.67 & 29.89 & 15.22 \\
\hline 23 & 32.81 & 35.70 & 29.92 & 15.31 \\
\hline 24 & 32.81 & 35.70 & 29.97 & 15.31 \\
\hline 25 & 32.85 & 35.83 & 29.99 & 15.70 \\
\hline 26 & 33.28 & 35.83 & 29.99 & 15.74 \\
\hline 27 & 33.57 & 36.00 & 30.45 & 16.25 \\
\hline 28 & 34.11 & 36.25 & 30.49 & 16.32 \\
\hline 29 & 34.29 & 36.51 & 31.14 & 16.48 \\
\hline 30 & 34.60 & 36.95 & 31.14 & 16.48 \\
\hline Mean & 30.37 & 34.63 & 28.48 & 14.79 \\
\hline SD & 2.71 & 1.150 & 1.505 & 0.934 \\
\hline
\end{tabular}

Conversion factor $\mathrm{MPa}=$ multiply by $0.1450 \mathrm{ksi}$ 
Table 15. flexural strength of FA concrete (in MPa)

\begin{tabular}{|c|c|c|c|c|}
\hline S1 No. & Control & $\begin{array}{c}20 \% \\
\text { replacement } \\
\text { by FA }\end{array}$ & $\begin{array}{c}40 \% \\
\text { replacement } \\
\text { by FA }\end{array}$ & $\begin{array}{c}60 \% \\
\text { replacement } \\
\text { by FA }\end{array}$ \\
\hline 1 & 5.94 & 5.51 & 3.94 & 2.90 \\
\hline 2 & 6.12 & 5.58 & 3.94 & 2.97 \\
\hline 3 & 6.47 & 5.69 & 4.16 & 3.03 \\
\hline 4 & 6.81 & 5.69 & 4.16 & 3.03 \\
\hline 5 & 6.06 & 5.82 & 4.18 & 3.09 \\
\hline 6 & 6.65 & 5.82 & 4.18 & 3.09 \\
\hline 7 & 6.16 & 5.84 & 4.26 & 3.20 \\
\hline 8 & 5.96 & 5.91 & 4.26 & 3.20 \\
\hline 9 & 6.82 & 5.96 & 4.29 & 3.20 \\
\hline 10 & 6.52 & 6.11 & 4.29 & 3.23 \\
\hline 11 & 5.63 & 6.11 & 4.30 & 3.23 \\
\hline 12 & 6.47 & 6.17 & 4.30 & 3.26 \\
\hline 13 & 6.15 & 6.24 & 4.32 & 3.26 \\
\hline 14 & 6.70 & 6.36 & 4.50 & 3.28 \\
\hline 15 & 5.87 & 6.39 & 4.53 & 3.30 \\
\hline 16 & 6.65 & 6.54 & 4.53 & 3.30 \\
\hline 17 & 6.19 & 6.54 & 4.61 & 3.31 \\
\hline 18 & 6.50 & 6.54 & 4.61 & 3.35 \\
\hline 19 & 6.34 & 6.54 & 4.62 & 3.35 \\
\hline 20 & 6.41 & 6.57 & 4.72 & 3.39 \\
\hline 21 & 5.63 & 6.58 & 4.76 & 3.39 \\
\hline 22 & 6.47 & 6.58 & 4.78 & 3.42 \\
\hline 23 & 6.15 & 6.74 & 4.86 & 3.46 \\
\hline 24 & 6.70 & 6.77 & 4.86 & 3.47 \\
\hline 25 & 5.87 & 6.77 & 4.88 & 3.47 \\
\hline 26 & 6.65 & 6.85 & 4.88 & 3.47 \\
\hline 27 & 6.19 & 7.10 & 5.03 & 3.47 \\
\hline 28 & 6.70 & 7.10 & 5.03 & 3.55 \\
\hline 29 & 5.87 & 7.14 & 5.07 & 3.55 \\
\hline 30 & 6.65 & 7.15 & 5.07 & 3.68 \\
\hline Mean & 6.32 & 6.36 & 4.53 & 3.33 \\
\hline $\mathrm{SD}$ & 0.33 & 0.48 & 0.34 & 0.18 \\
\hline
\end{tabular}

Conversion factor $\mathrm{MPa}=$ multiply by $0.1450 \mathrm{ksi}$ 
Table 16. split tensile strength of FA concrete (in MPa)

\begin{tabular}{|c|c|c|c|c|}
\hline Sl. No. & Control & $\begin{array}{c}20 \% \\
\text { replacement } \\
\text { by FA }\end{array}$ & $\begin{array}{c}40 \% \\
\text { replacement } \\
\text { by FA }\end{array}$ & $\begin{array}{c}60 \% \\
\text { replacement } \\
\text { by FA }\end{array}$ \\
\hline 1 & 2.21 & 1.98 & 1.66 & 1.17 \\
\hline 2 & 2.69 & 2.00 & 1.66 & 1.19 \\
\hline 3 & 2.64 & 2.01 & 1.70 & 1.24 \\
\hline 4 & 2.71 & 2.01 & 1.71 & 1.26 \\
\hline 5 & 2.67 & 2.14 & 1.73 & 1.28 \\
\hline 6 & 2.57 & 2.14 & 1.74 & 1.29 \\
\hline 7 & 2.46 & 2.17 & 1.74 & 1.29 \\
\hline 8 & 2.54 & 2.20 & 1.76 & 1.29 \\
\hline 9 & 2.67 & 2.21 & 1.77 & 1.31 \\
\hline 10 & 2.26 & 2.21 & 1.77 & 1.32 \\
\hline 11 & 2.61 & 2.23 & 1.77 & 1.35 \\
\hline 12 & 2.29 & 2.23 & 1.77 & 1.35 \\
\hline 13 & 2.73 & 2.29 & 1.78 & 1.36 \\
\hline 14 & 2.85 & 2.42 & 1.78 & 1.38 \\
\hline 15 & 2.18 & 2.42 & 1.79 & 1.38 \\
\hline 16 & 2.81 & 2.45 & 1.79 & 1.41 \\
\hline 17 & 2.35 & 2.46 & 1.79 & 1.41 \\
\hline 18 & 2.88 & 2.52 & 1.79 & 1.41 \\
\hline 19 & 2.90 & 2.52 & 1.81 & 1.41 \\
\hline 20 & 2.96 & 2.69 & 1.81 & 1.42 \\
\hline 21 & 2.67 & 2.72 & 1.84 & 1.43 \\
\hline 22 & 2.26 & 2.75 & 1.84 & 1.44 \\
\hline 23 & 2.61 & 2.79 & 1.85 & 1.45 \\
\hline 24 & 2.29 & 2.83 & 1.85 & 1.45 \\
\hline 25 & 2.64 & 2.85 & 1.86 & 1.46 \\
\hline 26 & 2.71 & 2.94 & 1.86 & 1.46 \\
\hline 27 & 2.67 & 2.94 & 1.87 & 1.49 \\
\hline 28 & 2.57 & 3.03 & 1.88 & 1.49 \\
\hline 29 & 2.46 & 3.10 & 1.89 & 1.52 \\
\hline 30 & 2.67 & 3.13 & 1.89 & 1.52 \\
\hline Mean & 2.60 & 2.48 & 1.79 & 1.37 \\
\hline SD & 0.23 & 0.35 & 0.063 & 0.093 \\
\hline
\end{tabular}

$*$ Conversion factor $\mathrm{MPa}=$ multiply by $0.1450 \mathrm{ksi}$ 
Fig. 1. Compressive strength distribution of FA concrete cubes

Fig. 2: Flexural strength distribution of FA concrete cubes

Fig. 3: Split tensile strength distribution of FA concrete cubes

Fig. 4: Cumulative Probability Distribution (experimental and assumed) for compressive strength

Fig 4 (a) Control

Fig 4 (b) 20\% FA

Fig 4 (c) $40 \%$ FA

Fig 4 (d) 60\% FA

Fig. 5: Cumulative Probability Distribution (experimental and assumed) for flexural strength

Fig 5 (a) Control

Fig 5 (b) $20 \%$ FA

Fig 5 (c) $40 \%$ FA

Fig 5 (d) $60 \%$ FA

Fig. 6: Cumulative Probability Distribution (experimental and assumed) for split tensile strength

Fig 6 (a) Control

Fig 6 (b) $20 \%$ FA

Fig 6 (c) $40 \%$ FA

Fig 6 (d) $60 \%$ FA

Fig. 7: Selected seismic hazard curve. (Adapted from Dhir et al. 2018, (C) ASCE.)

Fig. 8: Typical four-storey RC frame selected for the present study

Fig.9: PSDM for control and FA concrete frames

Fig. 10: Fragility curves for control and FA concrete

Fig 10 (a) At SD

Fig 10 (b) At CP

Fig. 11: Reliability curves for control and FA concrete

Fig 10 (a) At SD 
Fig 10 (b) At CP 